\title{
PAISAGEM DE EXCEÇÃO E OS PROBLEMAS AMBIENTAIS DA SERRA DE JOÃO DO VALE
}

\author{
Francisco Hermínio Ramalho de Araújo $^{(a)}$, Marco Túlio Mendonça Diniz ${ }^{(b)}$ \\ (a) SEEC, Universidade Federal do Rio Grande do Norte, Email: netinho_serra@ hotmail.com \\ (b) Departamento de Geografia, Universidade Federal do Rio Grande do Norte, Email: tuliogeografia@gmail.com
}

Eixo: GEODIVERSIDADE, GEOARQUEOLOGIA E PATRIMÔNIO NATURAL

\begin{abstract}
Resumo
O estudo da paisagem de forma integrativa ganhou perspectiva no Brasil com base na concepção geossistêmica de Bertrand (1971) e Sotchava (1977). O Brasil possui uma diversidade paisagística e no interior dos grandes domínios são encontradas paisagens diferenciadas representadas como enclaves ou paisagens de exceção. Tomando como referência os trabalhos de Ab'Saber (2003) o presente trabalho objetiva fazer uma análise integrada da paisagem e dos problemas ambientais da Serra de João do Vale sob a hipótese de ser esse ambiente uma serra úmida ou paisagens de exceção. Esse estudo requer o conhecimento da área como um todo, fazendo uma análise físicoecológica do ambiente e buscando conhecer as potencialidades paisagísticas e os efeitos das ocupações.
\end{abstract}

Palavras-chave: Paisagem de exceção. Problemas ambientais. Serra de João do Vale.

\section{Introdução}

A definição de paisagem é abordada por vários ramos da ciência, entre ele a Geografia. Nesta, vários geógrafos vem discutindo o conceito de paisagem. Santos (2008) discute a paisagem como tudo que a nossa visão consegue abarcar, sendo constituída de volumes, cores, movimentos, odores. De acordo com Souza (2015) o conceito de paisagem tem tradicionalmente um escopo mais específico ligado ao espaço onde a nossa vista abarca. Numa discursão desse conceito a partir de autores tradicionais Souza (2015) aponta como uma das virtualidades da paisagem é a capacidade de ser integradora das relações sociedade e natureza. Segundo Freire (2007) a análise da paisagem tem o objetivo de demonstrar a configuração físico-ambiental da região

A paisagem no Brasil apresenta em toda sua extensão territorial um grande e diversificado mostruário ecológico (FREIRE, 2007). Segundo Ab’Saber (2003) feições paisagísticas e ecológicas ocorrem em uma espécie de área dimensional extensa e relativamente homogênea denominada de domínio de natureza. Segundo Freire (2007) o interior desses grandes domínios são moldados por pequenos quadros de paisagens diferenciadas representadas como enclaves, constituindo assim como uma paisagem de exceção.

O termo paisagem de exceção foi estudado por Ab'Saber (2003) no qual é definido como sendo fatos isolados, de diferentes aspectos físicos e ecológicos inseridos no corpo geral das paisagens habituais. 


\section{OS DESAFIOS DA GEOGRAFIA FÍSICA NA FRONTEIRA DO CONHECIMENTO \\ Instituto de Geociências - Unicamp \\ Campinas - SP \\ 28 de Junho à 02 de Julho de 2017}

Dentre as paisagens de exceção existente no Brasil classificadas por Ab’Saber (2003) temos: topografias ruiniformes; pontões rochosos do tipo "pão de açúcar", penedos ou "dedos de Deus", comuns na região Sudeste; o interior do canyons brasileiros, o Pantanal mato-grossense, agrupamentos de inselbergs, dentre outros.

No Nordeste brasileiro os inselbergs aparecem como forma de montes e ilhas rochosas sob o domínio das caatingas. Nessa região também há ocorrência de maciços elevados (900-1000 m) voltados para ventos úmidos (barlavento) provenientes de leste e sudeste (AB'SABER, 2003). Para o mesmo as ilhas de umidades ou serras úmidas, assim denominadas pelo autor, ocorrem em plenos sertões secos, constituindo-se como verdadeiras ilhas de umidade, redutos de florestas tropicais e com seus habitantes adaptados a atividades agrárias. A biodiversidade dessas florestas úmidas do sertão ainda é muito pouco conhecida, mas é bem provável que guarde surpresas, seja por seu longo isolamento ou por terem pertencido originalmente a um dos biomas mais diversificados da Terra (CALVALCANTE, 2005).

Souza e Oliveira (2006) realizaram um estudo sobre os enclaves úmidos e subúmidos por Estado do Nordeste Brasileiro, no domínio fitogeográfico da Caatinga. Neste trabalho não foi estudado o Rio Grande do Norte (RN), mas não significa dizer que nesse estado não existam serras úmidas. Ab'Saber (2003) cita uma altimetria dos enclaves estudados que eram de 900 à 1000 metros, mas não podemos apenas utilizar esse valor como referência. Pois outros critérios, de ordem física e ecológico, foram estabelecidos por ele para identificar as serras úmidas da região. Esses critérios servem de argumentos para classificar e identificar os enclaves úmidos no RN.

No RN alguns maciços como a Portalegre, Martins e João do Vale podem ser caracterizados como ilhas de umidades ou serras úmidas. Trata-se de platôs da ordem de $700 \mathrm{~m}$ de altitude que emergem sobre a topografia aplainada da Depressão Sertaneja (MAIA, 2012). Esses platôs se formam em capeamento sedimentar que repousa sobre o embasamento cristalino, conhecido como Formação Serra dos Martins (MENEZES, 1999). A exuberância paisagística desses ambientes são fatores que demostram o contraste com o seu entorno. Tal fato justifica-se pelo comportamento de um ambiente diferenciado, onde a altitude possibilita a existência de condições climáticas que favorecem a ocorrência de formações vegetais úmidas no domínio semiárido das caatingas.

Diante do exposto o presente trabalho tem como objetivo fazer uma análise integrada da paisagem e dos problemas ambientais da Serra de João do Vale sob a hipótese de ser esse ambiente uma serra úmida ou paisagens de exceção no semiárido do Nordeste brasileiro.

O fato de não existir ainda estudo voltado para análise desse ambiente numa perspectiva integrada da paisagem classificando João do Vale como uma serra úmida foi fundamental para a escolha do tema e do objetivo desse trabalho. 


\section{Materiais e Métodos}

A Serra de João do Vale está situada nos municípios de Campo Grande, Triunfo Potiguar e Jucurutu, no estado do RN, e Belém do Brejo do Cruz, Paraíba. Sendo que nas partes habitadas são administradas politicamente apenas por Triunfo Potiguar e Jucurutu.

Para a realização deste trabalho, inicialmente, foi realizado um levantamento bibliográfico acerca dos principais autores que abordaram o tema em questão. Ab'Saber (1999, 2003), com seus respectivos trabalhos sobre serras úmidas e domínios de natureza do Brasil, foi o principal aporte teórico que norteou a pesquisa. Outras bibliografias também deram suporte no embasamento teórico desse estudo.

Esta pesquisa foi fundamentada no estudo integrativo da paisagem, com base na concepção geossistêmica. Vários teóricos foram consultados mas a obra de Ab'Saber sobre as paisagens de exceção no semiárido brasileiro foi o principal aporte teórico desse trabalho.

Para análise da paisagem de forma integrativa teve como base a concepção geossitêmica de Bertrand (1971) e Sotchava (1977). O estudo sobre geossistema é baseado na Teoria Geral dos Sistemas de Bertalanffy (1968), no qual propõe que os sistemas são definidos como conjuntos de elementos com variáveis características diversas, que mantêm relações entre si e entre o meio ambiente (RODRIGUES 2001). Bertrand (1971) elaborou um esboço teórico para explicar o funcionamento do Geossistema (FIGURA 01).

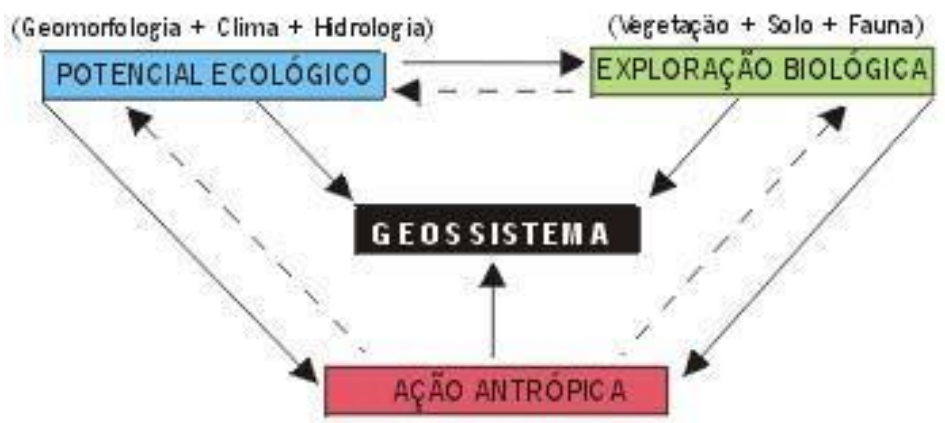

Figura 01: Elementos que compõe as relações ambientais Fonte: Bertrand (1971).

Pode se observar que a estrutura e a dinâmica resultam da interação entre o potencial ecológico, a exploração biológica e a ação antrópica, e que se identifica por um mesmo tipo de evolução. Esse método é muito utilizado para o estudo da paisagem de forma integrada, sendo muito útil para alcançar os objetivos desta pesquisa. 


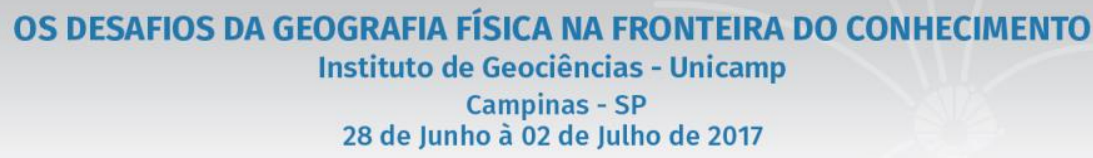

A pesquisa de campo foi indispensável e fundamental para a realização desse trabalho. Em campo foi realizado uma análise da paisagem visando à caracterização dos aspectos físico e naturais, atentando para os problemas ambientais decorrentes da relação homem e natureza.

Para a análise da paisagem na área de estudo também foram realizados registros fotográficos acerca dos aspectos da paisagem do local. Os dados coletados em campo foram confrontados com os dados bibliográficos, para poder chegar a um diagnóstico acerca das características do ambiente.

Esta pesquisa teve caráter descritivo e exploratório, uma vez que é pioneira para essa temática na área.

\section{Resultados e Discussões}

A Serra de João do Vale se localiza dentro dos municípios que de acordo com o CPRM (2005) estão inseridos geologicamente na Província da Borborema (Campo Grande, Triunfo Potiguar, Jucurutu e Belém do Brejo do Cruz). A província da Borborema é composta por agrupamentos de rochas metamórfica e ígneas (MAIA \& BEZERRA, 2014). A geologia da Serra de João do Vale pode se dividida em dois grupos: embasamento cristalino e rochas sedimentares.

As rochas cristalinas são corpos de granitoides brasilianas formados no Neoproterozoico do período Pré-Cambriano de idade entre 630 a 540 ma (MEDEIROS et al. 2010) (FIGURA 02). A Serra de João do Vale é afetada por zonas de cinzalhamento brasilianas com trends NNE da Faixa Seridó (JARDIM DE SÁ, 1994. apud MENEZES, 1999)

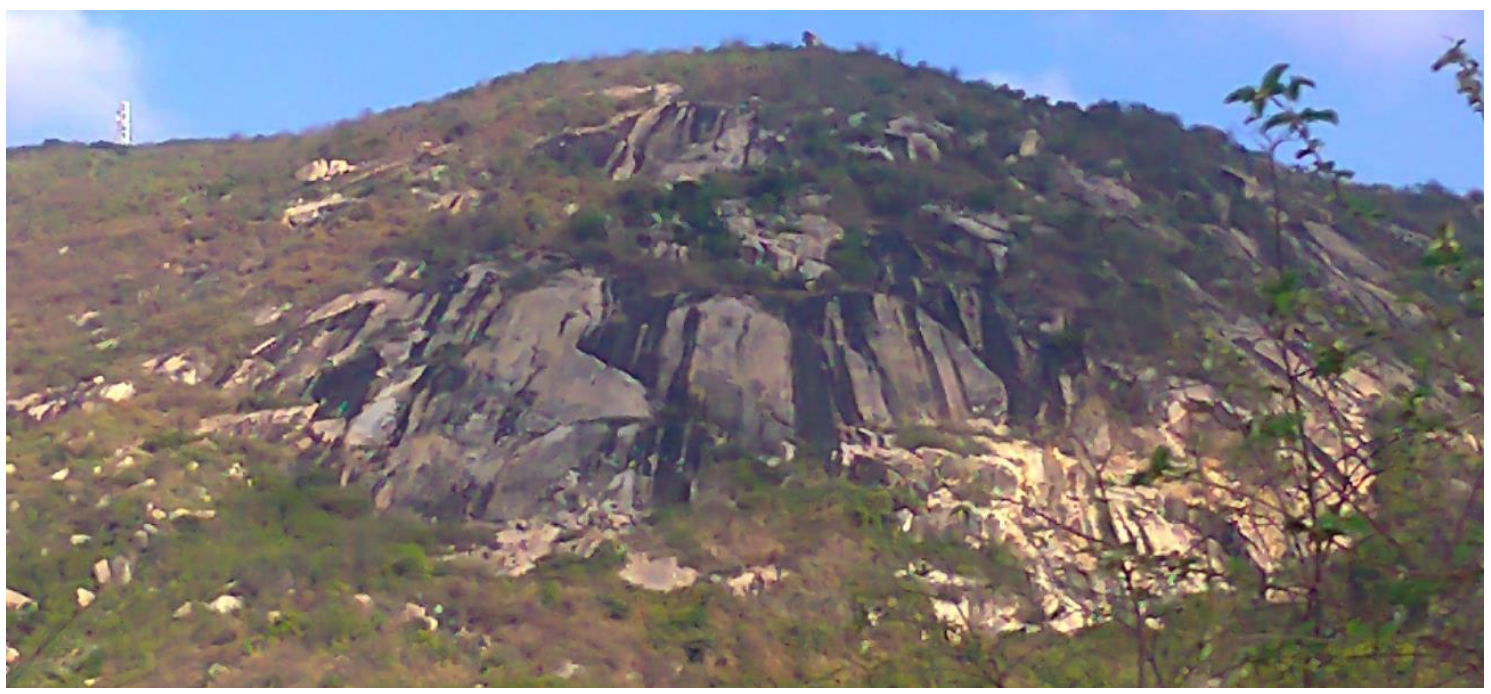

Figura 02: Embasamento cristalino na Serra de João do Vale Foto: Acervo do autor (2011).

As rochas sedimentares são constituídas por arenitos médios a conglomeráticos, argilosos e crosta laterítica com seixos de quartzo que corresponde a Formação Serra dos Martins (FMS) de idade oligomiocênica, aproximadamente 23 milhões de anos (MEDEIROS et al., 2010) (FIGURA 03). A 
XVII Simpósio Brasileiro

de Geografia Fisica Aplicada

I Congresso Nacional

de Geografia Física

\section{OS DESAFIOS DA GEOGRAFIA FÍSICA NA FRONTEIRA DO CONHECIMENTO \\ Instituto de Geociências - Unicamp \\ Campinas - SP \\ 28 de Junho à 02 de Julho de 2017}

Formação Serra dos Martins é o nome atribuído às coberturas sedimentares que capeiam as serras interioranas com cotas superiores a $600 \mathrm{~m}$. No RN a FSM está presente nos topos das serras de Martins, Portalegre, João do Vale, Santana e Monte das Gameleiras (MENEZES, 1999).

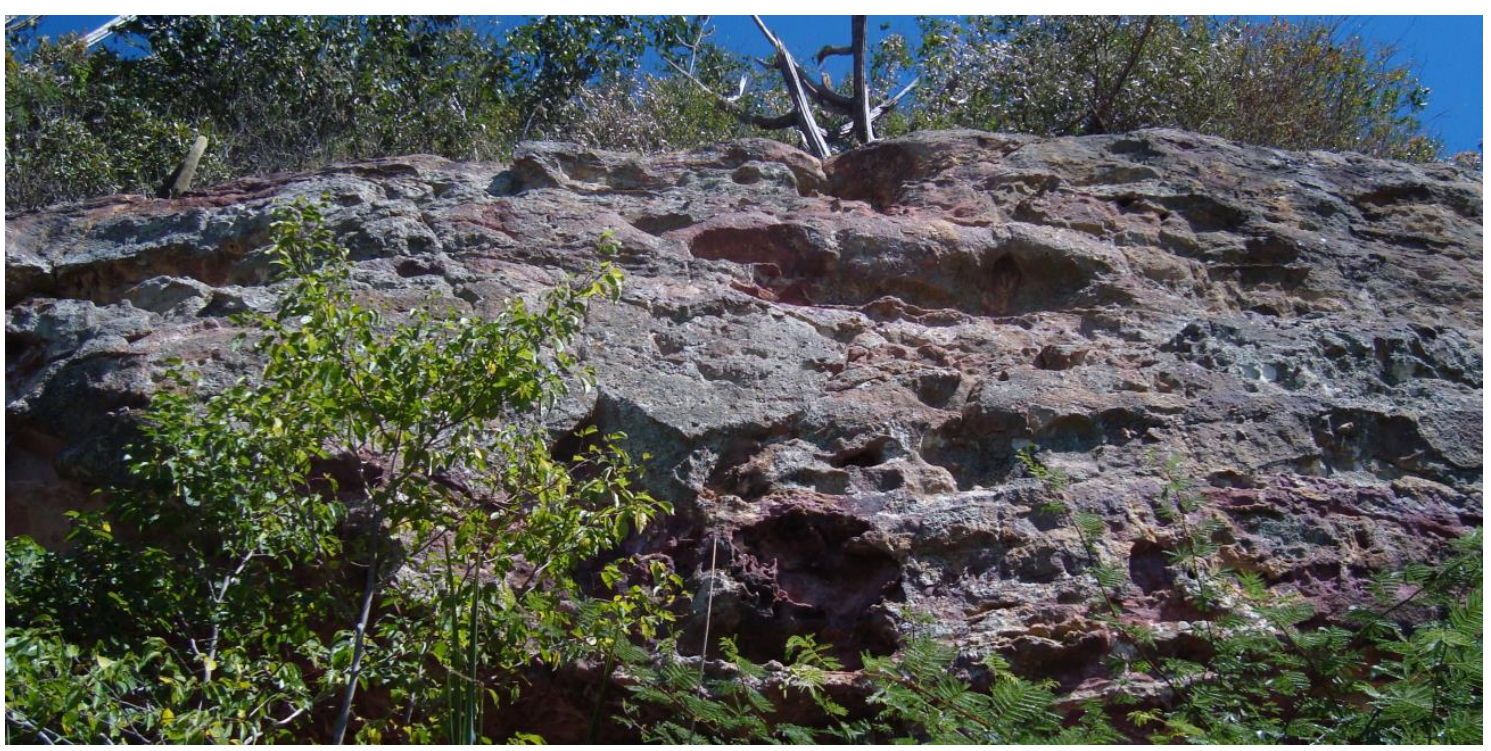

Figura 03: Afloramento de arenitos da Formação Serra dos Martins na Serra de João do Vale. Foto: Acervo do autor (2013).

Pelo fato de ser capeada por rochas recentes de idade aproximadamente 23 Ma que estão expostas em cima de estruturas cristalinas bem mais antigas, 630-540 Ma, comprova que essa área sofreu um soerguimento recente do ponto de vista geológico contrariando as concepções clássicas sobre a evolução do relevo do Nordeste brasileiro, pois na área é marcante a inversão do relevo por neotectônica. Maia (2012) tem apresentado estudos comprovando que houve uma série de eventos tectônicos ocorrido na região Nordeste desde o final do Neógeno até o Quaternário. Esses eventos são designados de neotectônica e alguns estão relacionados à migração da placa sul-americana para Leste e às tensões, geralmente compreensivas, intra-placa (MAIA \& BEZERRA, 2014). Essas evidências comprovam que a Serra de João do Vale passou por um processo de neotectônica, o que resultou no seu soerguimento. MAIA et al. (2013) num trabalho de classificação das unidades geomorfológicas do RN identifica João do Vale como um maciço estrutural.

$\mathrm{Na}$ Serra de João do Vale o relevo se apresenta com o topo tipicamente plano e arenítico (FIGURA 04). Essas características se dão devido ao capeamento sedimentar da Formação Serra dos Martins que repousa sobre as rochas do embasamento cristalino do platô. A cota altimétrica máxima do platô está em torno de $740 \mathrm{~m}$. 

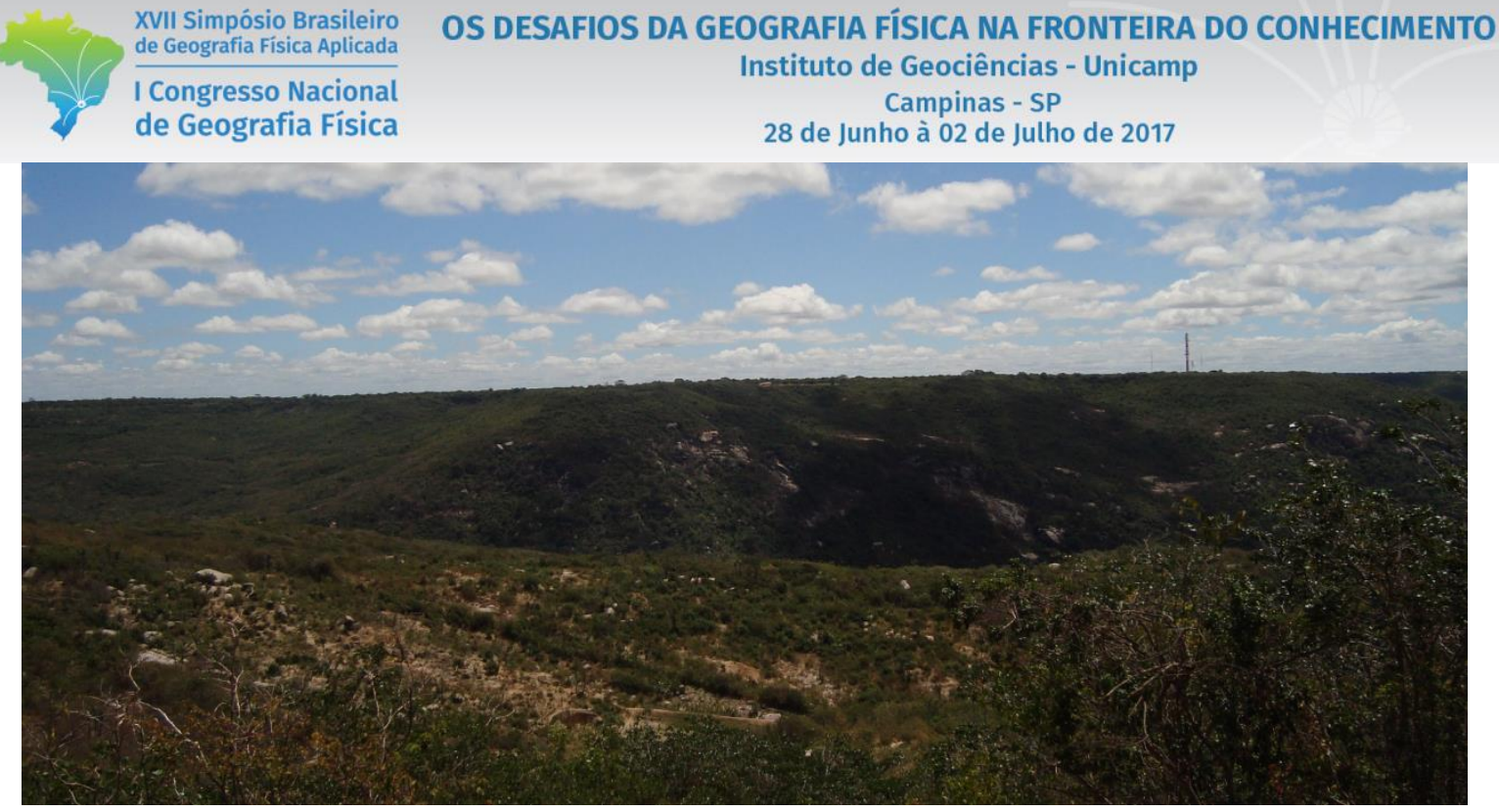

Figura 04: Relevo em forma de chapada da Serra de João do Vale.

Fonte: Acervo do autor (2013).

A altitude exerce considerável influência na distribuição das chuvas e nas temperaturas. Em João do Vale os índices pluviométricos anuais variam de 800 a $900 \mathrm{~mm}$ (DINIZ \& OLIVEIRA, 2015) e a temperatura média em torno de $22{ }^{\circ} \mathrm{C}$. Devido à altitude e à natureza das rochas permeáveis são encontradas na Serra de Martins formações vegetais densas e solos bem desenvolvidos com características de lugares úmidos.

A vegetação encontrada na Serra de João do Vale quebra a continuidade dos sertões semiáridos revestidos de Caatinga (FIGURA 05). No interior do RN, nas serras úmidas, há ocorrência de formações associadas à Mata Atlântica. São os Brejos de Atitudes encontrados nas Serras de Martins, Portalegre, São Miguel e também em João do Vale. Nesta última foi constatada em campo a presença de um tipo de formação vegetal mais densa com variedades de espécies, predominando principalmente no platô e nas encostas a barlavento, onde recebem os ventos provenientes de sudeste. Já nas escarpas que se localizam a sotavento foi encontrado uma maior presença da Caatinga com arbustos mais esparsos. 


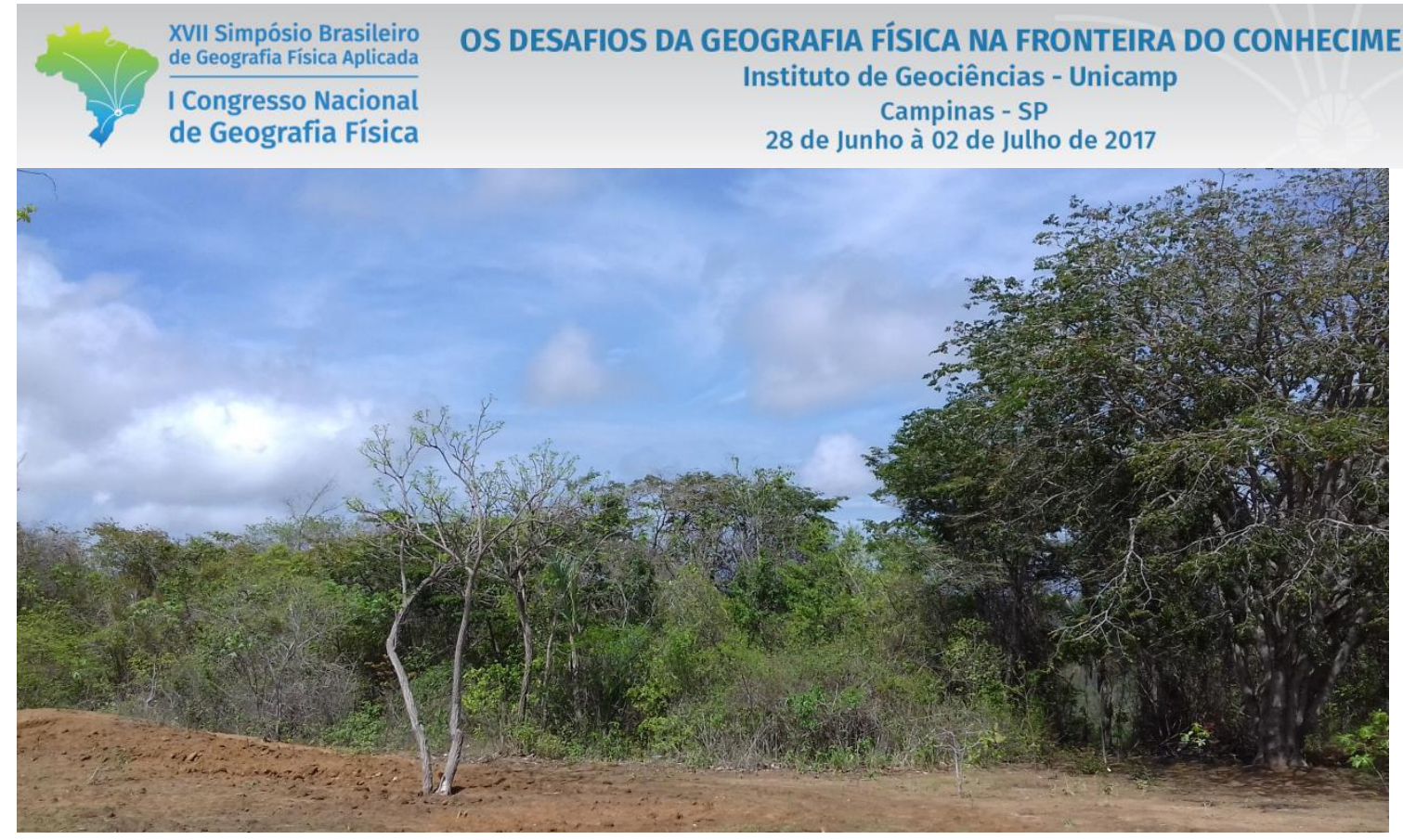

Figura 05:Aspecto da formação vegetal da Serra de João do Vale.

Fonte: Acervo do autor (2017).

Os solos são bem desenvolvidos com o predomínio do Latossolo Vermelho-Amarelo que contrastam com os das caatingas. São solos vermelho-amarelos da classe dos Oxissolos diferentes dos solos brunos, rasos e pedregosos do Sertão semiárido. "O povo do Nordeste interior quando fala de solo vermelho invoca sempre a ideia de terra fértil”" (AB'SABER, 1999, p. 30). Na Serra de João do Vale a sua população tem essa crença e acredita na alta fertilidade do solo do platô (FIGURA 06).

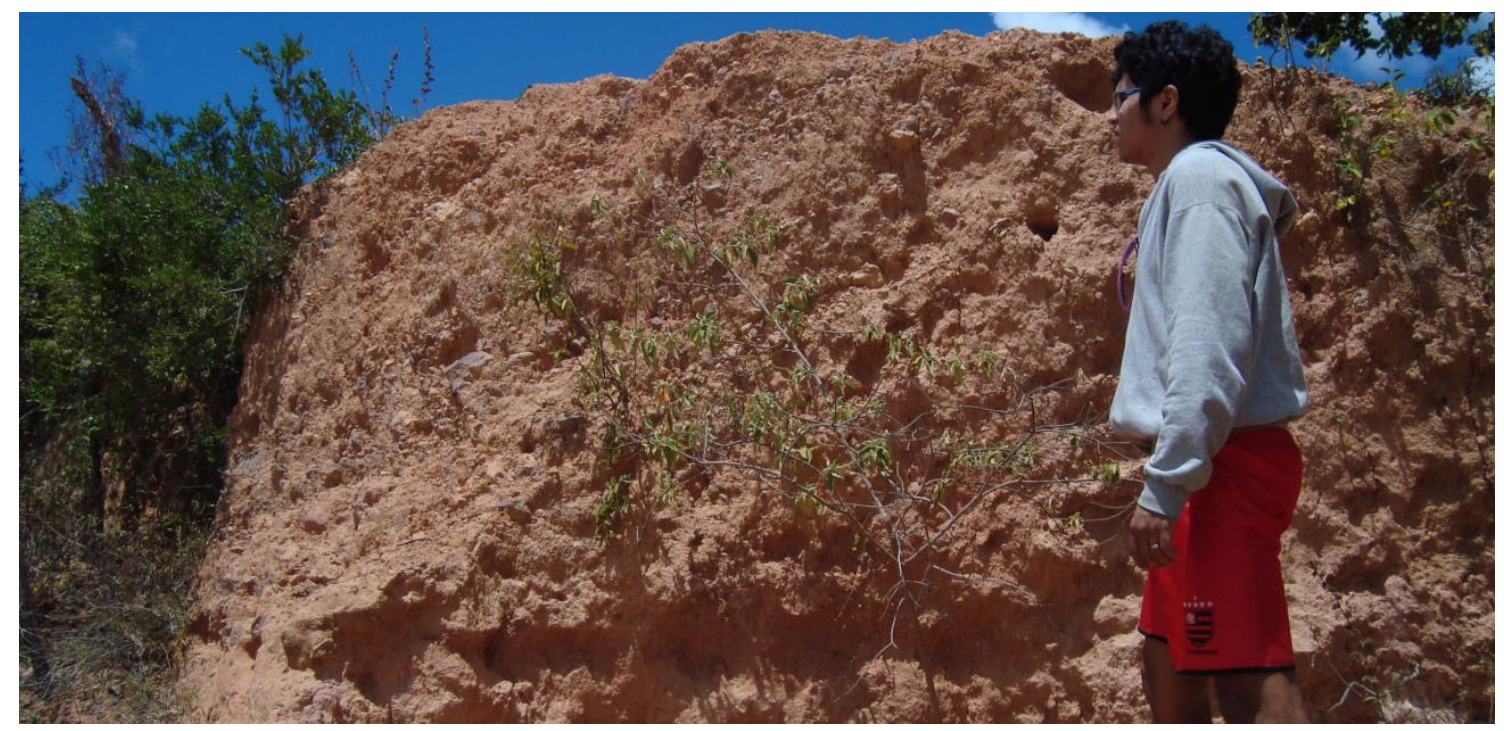

Figura 06:Aspecto do solo na Serra de João do Vale.

Fonte: Acervo do autor (2013).

Esses lugares foram denominados por Ab'Saber (1999) de serras úmidas, podendo ser classificadas como paisagens de exceção, com enclaves de florestas úmidas que quebram a monotonia do semiárido e são dotadas de mini-drenagens perenes. No caso da Serra de João do Vale tem em suas encostas olhos d'águas perenes, mas não formam drenagens perenes. 


\section{OS DESAFIOS DA GEOGRAFIA FÍSICA NA FRONTEIRA DO CONHECIMENTO Instituto de Geociências - Unicamp \\ Campinas - SP \\ 28 de Junho à 02 de Julho de 2017}

$\mathrm{Na}$ Serra de João do Vale as populações locais se envolvem em atividades agrícolas tradicionais e a produção de frutas tropicais. Algumas culturas são produzidas pela comunidade só para o consumo familiar, no contexto de agricultura de subsistência, como o milho, a fava, o feijão, etc. Outras são praticadas com fins lucrativos, entre elas a produção do caju, e principalmente a comercialização da castanha do caju (FIGURA 07).

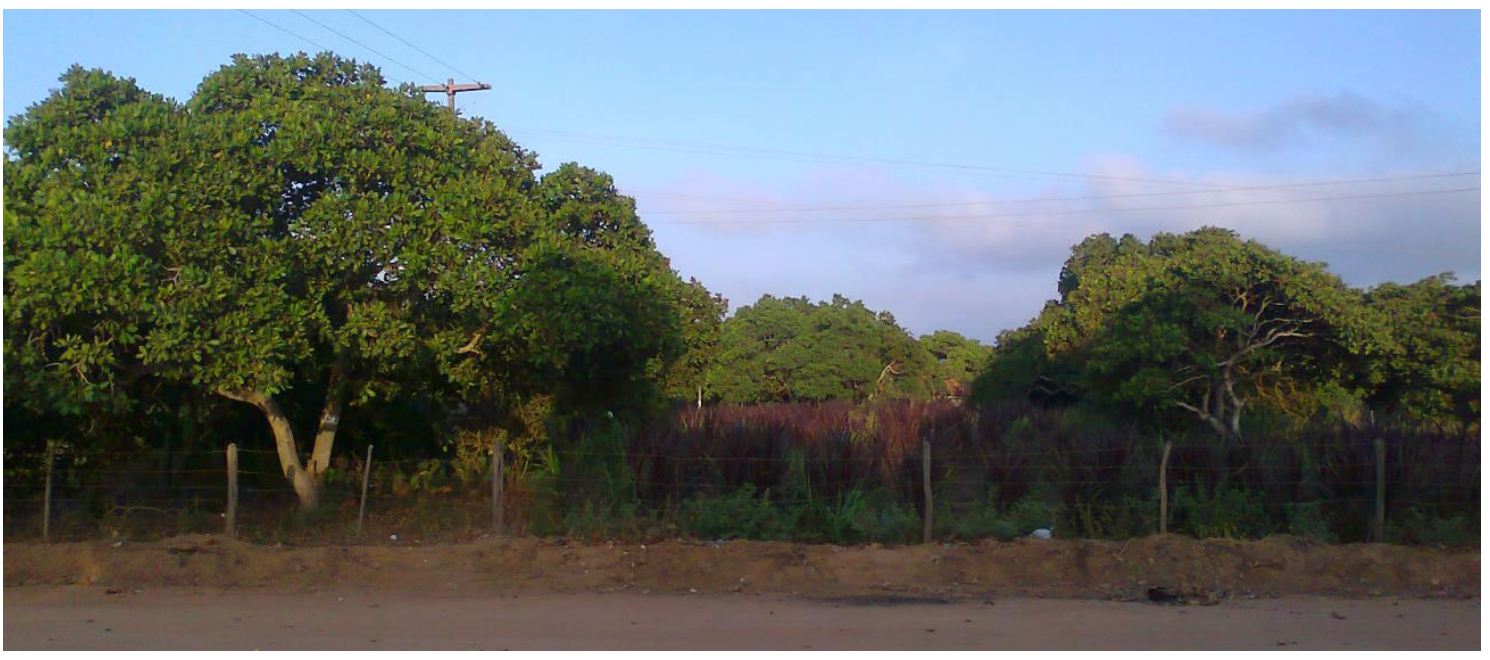

Figura 07: Plantação de cajueiro.

Fonte: Acervo do autor (2011).

A cajucultura foi a atividade que mais se destacou na economia da Serra de João do Vale; na época da colheita essa atividade gerava lucro para a comunidade, pois o capital circulava com mais facilidade, fazendo com que as pessoas pudessem suprir as suas necessidades, tendo em vista que a maior parte da população dessa comunidade é constituída por famílias de baixa renda. Recentemente esta atividade parece não ser mais tão importante e sua produção caiu, principalmente após o desmatamento do cajueiro para a comercialização da lenha para as cerâmicas do Seridó e do Vale do Açu.

Atualmente outras atividades que vem se destacando na economia da Serra de João do Vale são a agricultura orgânica e o turismo. O primeiro é praticado por famílias de baixa renda que foram beneficiadas com cisternas e cisternões, projeto do governo federal, e vendem seus produtos no mercado local e na feira livre na cidade de Jucurutu.

O turismo é a atividade econômica que parece que vai ganhar relevância nos próximos anos. Tal fato se atribui ao grande potencial turístico que a Serra de João do Vale possui, revelando em suas belas paisagens naturais que podem ser vistas principalmente dos mirantes por visitantes que vêm de diversos locais do Estado. Parte da comunidade está se voltando para essa atividade, as especulações imobiliárias elevaram os preços dos terrenos, casas e chalés estão sendo construídos em mirantes (FIGURA 08). 

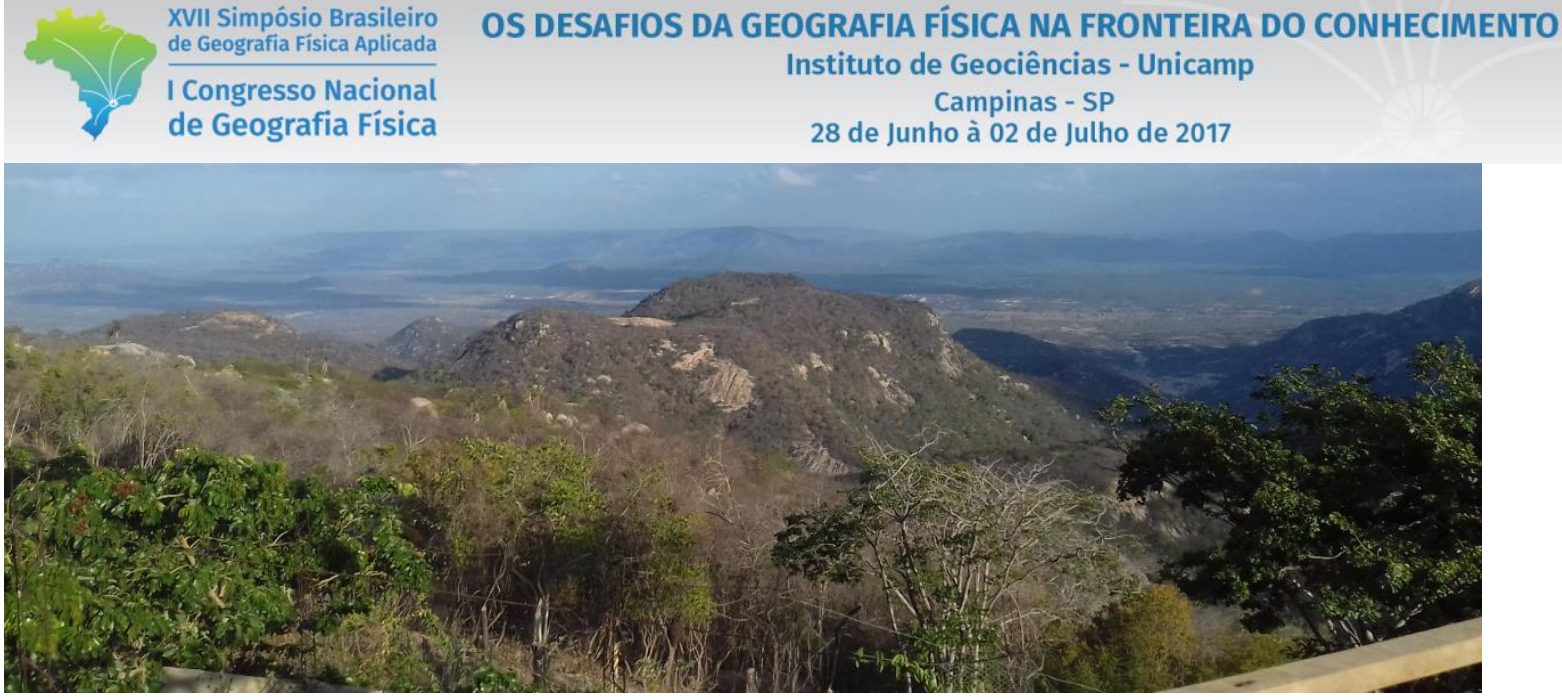

Figura 08: Aspecto da paisagem de um mirante na Serra de João do Vale.

Fonte: Acervo do autor (2017).

A serra de João do Vale parece ter encontrado uma nova atividade econômica que vai gerar renda para suas populações, o turismo. Só que o acesso ao platô é ainda um problema para que essa atividade se efetive de fato, pois as estradas não são pavimentadas e nos períodos chuvosos ficam muitas deterioradas.

A mata nativa se encontra reduzida, sendo substituída por plantas frutíferas, plantações e pelas construções. A atividade agrícola praticada na Serra de João do Vale é caracterizada, em sua maior parte, pelo uso de técnicas rudimentares. A queimada é a mais utilizada pela população local e seu uso acarreta numa serie de danos ao meio ambiente como a poluição do ar e a perda da fertilidade do solo.

Outro problema ocasionado pelas atividades agrícolas é o uso de áreas inadequadas, dá-se, muitas vezes, pelo fato de desconhecimento dos problemas ambientais que podem ocasionar e também pela falta de alternativa de produção por parte de agricultores alocados em pequenas propriedades de terra, que se limitam à produção nas escarpas do platô. Dentre os impactos que podem ocorrer pode se destacar a erosão dos solos que provoca o afloramento do substrato rochoso e a perda da fertilidade do solo.

O grande potencial turístico da Serra de João do Vale tem contribuído um pouco para a redução da vegetação. As encostas estão sendo desmatadas para se tornarem lugares mais atrativos para os turistas, e consequentemente aumentar a especulação imobiliária. (FIGURA 09) A comercialização fácil de terrenos e as construções sem que haja uma fiscalização dos órgãos públicos contribui para o aumento desse problema. 


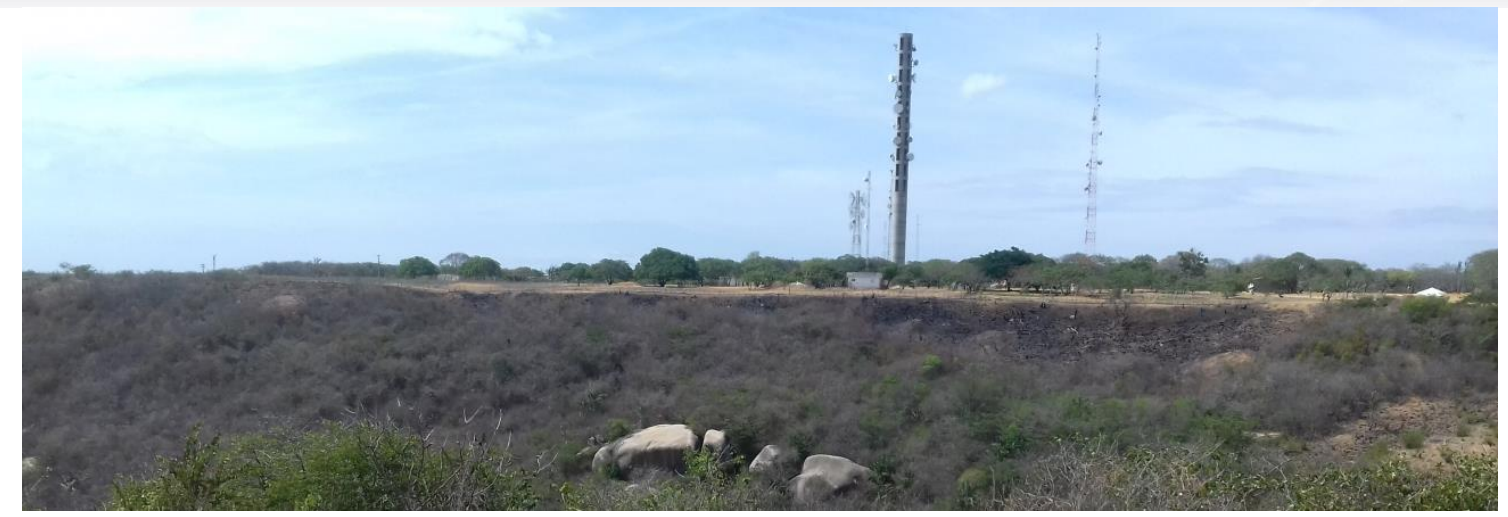

Figura 09: Áreas de encostas desmatadas na Serra de João do Vale.

Fonte: Acervo do autor (2017)

Existem construções próximas às escarpas, com risco de desabamentos, e terrenos submetidos a desmatamento desordenado. Nessas áreas pode-se perceber que a vegetação é impedida de se desenvolver, nesses locais, pois se conserva as paisagens de mirantes com a ausência da mata nativa. Isso contribui para a devastação da floresta nativa do platô.

As serras úmidas são importantes setores de dispersão de drenagem, fontes de água natural, que pela sua própria topografia são distribuídas através dos sistemas de bacias (FREIRE, 2007). Na Serra de João do Vale as mini-drenagens perenes, ou os olhos d'água, como são conhecidos no senso comum, estão seriamente ameaçadas com a devastação da cobertura vegetal que poderá ocasionar o ressecamento da fonte de água natural (FIGURA 10).

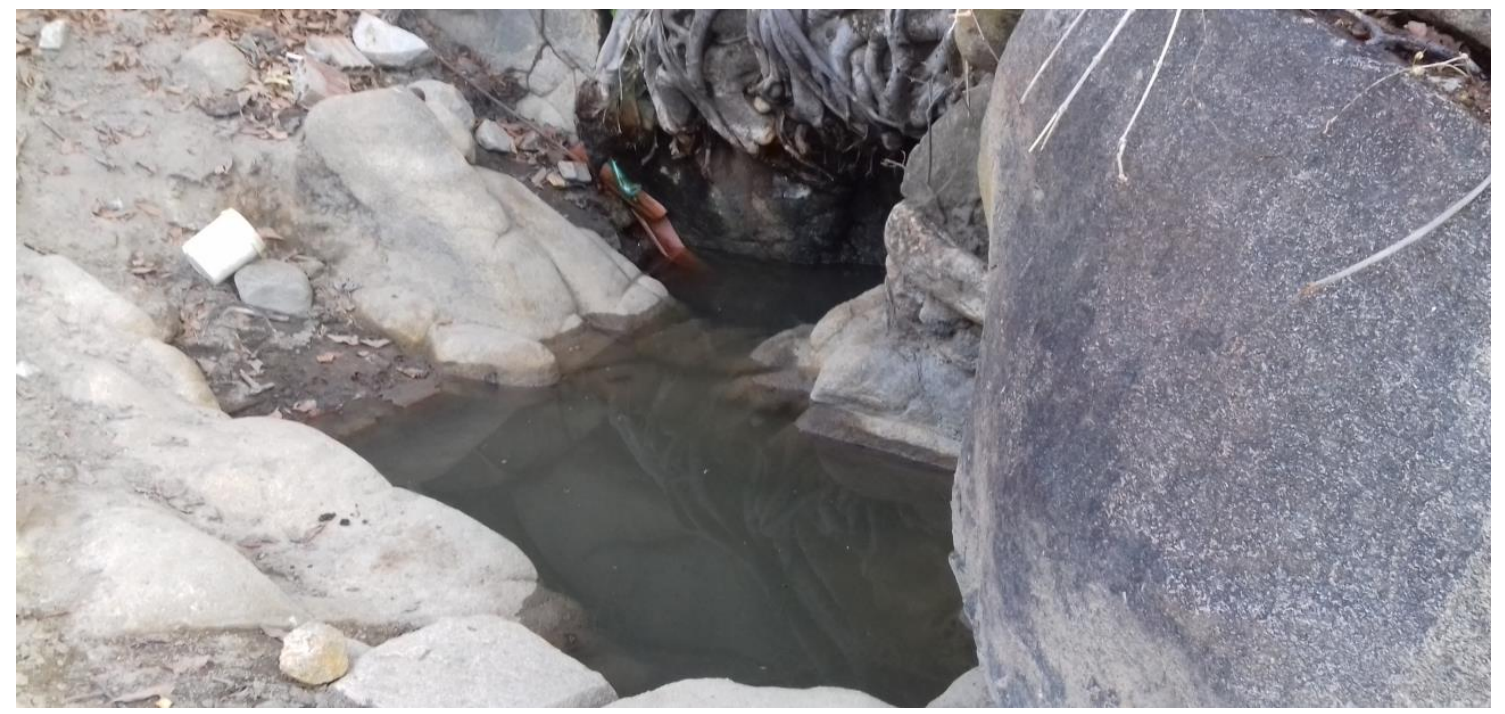

Figura 10: Olho d' água aflorando entre as rochas do embasamento cristalino em João do Vale. Fonte: Acervo do autor (2016).

Historicamente os olhos d'águas foram fontes de abastecimento da população local, principalmente no período de estiagem. Atualmente com a seca que vem se arrastando há mais de cinco anos, essas 


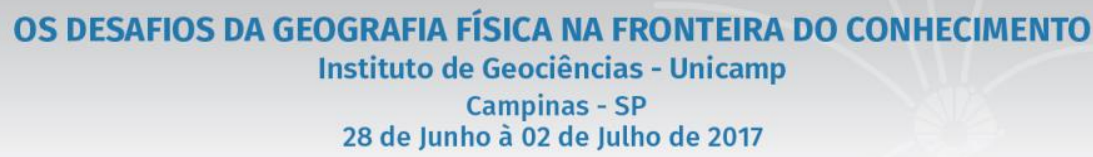

fontes estão abastecendo parte da população, pois as águas da adutora Meio Oeste não estão chegando às casas dos moradores.

\section{Considerações Finais}

Este estudo pode servir de base para a elaboração de planos para preservar as potencialidades paisagísticas da Serra de João do Vale, Promovendo a interação entre a natureza e a sociedade de uma maneira que se gere o desenvolvimento sustentável, aproveitando as riquezas da área sem comprometer as gerações futuras.

Foi constatado que a crescente ocupação do platô, a prática de atividades agrícolas de forma inadequada e a devastação dos recursos naturais têm comprometido seriamente a manutenção da paisagem natural original que dá ma especificidade ao lugar.

Espera-se que este trabalho sirva de referência para futuros estudos ou planos de desenvolvimento sobre a Serra de João do Vale, pois este fez uma análise integrada da paisagem, seja no que se refere aos aspectos geológicos, geomorfológicos, climáticos e florísticos, seja aos aspectos sociais. E que torne mais amplo e difundido o conhecimento da Serra de João do Vale como uma Serra Úmida ou paisagem de exceção no Semiárido brasileiro.

\section{REFERÊNCIA}

AB'SÁBER, A. N. Sertões e sertanejos: uma geografia humana sofrida. Dossiê Nordeste Seco, RevistaEstudosAvançados 13 (35). São Paulo, SP: USP, 1999, pp. 60-68.

.Os Domínios de Natureza no Brasil: potencialidades paisagísticas. São Paulo, SP: Ateliê Editorial,2003.

BERTALANFFY, L. V. Teoria Geral dos Sistemas. Petrópolis, Vozes, 1968.

BERTRAND, G. Paisagem e geografia global: esboço metodológico. Cadernos de Ciências da Terra, v. 13, p. 1-27. 1971

CAVAlCANTE, A. Jardins Suspensos no Sertão. Scientific American Brasil, São Paulo, v. 32, p. 66-73, 2005.

CPRM - SERVIÇO GEOLÓGICO DO BRASIL. Projeto cadastro de fontes de abastecimento por água subterrânea. Recife: CPRM/PRODEEM, 2005.

DINIZ, M. T. M.; OLIVEIRA, G. P. Compartimentação e caracterização das unidades de paisagem do Seridó Potiguar. Brazilian Geographical Journal: Geosciences and Humanities research medium, Ituiutaba, v. 6, n. 1, p. 291-318, jan./jun. 2015.

FREIRE, L. M. Paisagensde exceção: problemas ambientais no Município de Mulungu, serra de Baturité. Dissertação (Mestrado em Geografia) - UEC, Fortaleza, 2007. 134p.

MAIA, R. P. Geomorfologia e Neotectônica no Vale do Apodi-Mossoró RN. 2012. 218 f. Tese (Doutorado em Geodinâmica e Geofísica) - Natal: UFRN/PPGG, 2012.

MAIA, R. P.; BEZERRA, F. H. R. Tópicos de Geomorfologia estrutural: Nordeste brasileiro. Fortaleza: edições UFC, 2014. 
MAIA, R. P. et al. Geomorfologia do Rio Grande do Norte. In: ALBANO, Gleydson Pinheiro; FERREIRA, L. S.; ALVES, A. M. (Org.). Capítulos de Geografia do Rio Grande do Norte. 1. ed. Natal: Manimbu, 2013.

MEDEIROS, V. C. et al. Geologia. In: PFALTZGRAFF, Pedro Augusto dos Santos; TORRES, Fernanda Soares de Miranda (org.). Geodiversidade do estado do Rio Grande do Norte. Recife: CPRM, 2010.

MENEZES, M. R. F. Estudos Sedimentológicos e o Contexto Estrutural da Formação Serra do Martins, nos Platôs de Portalegre, Martins e Santana/RN. Dissertação (Mestrado em Geografia) UFRN, Natal, 1999.

RODRIGUES, C. A teoria geossistêmica e sua contribuição aos estudos geográficos e ambientais. São Paulo, Revista do Departamento de Geografia - USP, 14, 2001.

SANTOS, M. Paisagem e Espaço. Metamorfose do Espaço Habitado:Fundamentos Teóricos e Metodológicos da Geografia. São Paulo: EDUSP, 2008.

SOTCHAVA, V. B. O estudo dos geossistemas. Métodos em questão.n. 16, IGEOG-USP, São Paulo, $1977.51 \mathrm{p}$

SOUZA, M. J. N.; OLIVEIRA, V. P. V. Os enclaves úmidos e sub-úmidos do Semi-árido do Nordeste brasileiro. Mercator, v. 05, n. 09, p. 85-102. 2006.

SOUZA, M. L. Os conceitos fundamentais da pesquisa sócio-espacial. $2^{\mathrm{a}}$ ed. Rio de Janeiro: Bertrand Brasil, 2015. 